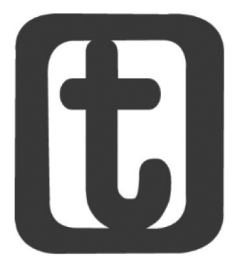

\title{
QUANDO A REALIDADE CALA: VIOLÊNCIA PSICOLÓGICA INTRAFAMILIAR CONTRA CRIANÇAS E ADOLESCENTES EM MOSSORÓ-RN
}

\section{WHEN REALITY SILENCES: INTRAFAMILY PSYCHOLOGICAL VIOLENCE AGAINST CHILDREN AND ADOLESCENTS IN MOSSORÓ-RN}

\author{
Gláucia Russo' \\ Hiago Trindade ${ }^{2}$ \\ Juliana Dantas 3 \\ Jéssica Nogueira ${ }^{4}$
}

\section{RESUMO}

O presente artigo busca refletir sobre a violência intrafamiliar contra crianças e adolescentes em Mossoró-RN, entre 2009 e 2012, particularmente em sua modalidade psicológica. Para tanto, foram realizadas revisão de literatura e pesquisa documental a partir dos prontuários do CREAS. Entre outras reflexões, os dados apontam para uma oscilação entre o número (a nosso ver, reduzido e distante da realidade concreta) denunciado de casos de violência psicológica intrafamiliar na cidade estudada, demonstrando sua invisibilidade e a necessidade de quebrar

1 Doutora em Ciências sociais pela Universidade Federal do Rio Grando do Norte (UFRN). Atualmente é pesquisadora e professora adjunto da Universidade do Estado do Rio Grande do Norte. E-mail: ghar@ibest.com.br.

2 Bacharel em Serviço Social pela Universidade do Estado do Rio Grande do Norte (UERN). Mestrando em Serviço Social pela Universidade Federal do Rio Grando do Norte (UFRN). Atualmente é professor substituto da Faculdade de Serviço Social da UERN. E-mail: hiagolira@hotmail.com.

3 Bacharel em Serviço Social pela Universidade do Estado do Rio Grande do Norte. E-mail: jujugrasiela@gmail.com.

4 Bacharel em Serviço Social pela Universidade do Estado do Rio Grande do Norte (UERN) e mestrando em Serviço Social pela mesma Universidade. E-mail: jessicanogueira1@bol.com.br. 


\section{temporalis}

o silêncio que a rodeia, desnaturalizando-a e contribuindo para a garantia dos direitos fundamentais de crianças e adolescentes.

Palavras-chave: Violência. Violência psicológica. Violência intrafamiliar. Criança. Adolescente.

\section{ABSTRACT}

This article aims to reflect on intrafamily violence against children and adolescents in Mossoró, RN, from 2009 to 2012, particularly in its psychological mode. For this purpose, we performed a literature review and desk research from the records of the CREAS. Among other considerations, the data point to an oscillation between the number (in our view, small and distant from reality) of reported cases of intrafamily psychological violence in the studied city, demonstrating their invisibility and the need to break the silence that surrounds it, denaturalizing it and contributing to the guarantee of children and adolescents fundamental rights.

Keywords: Violence. Psychological violence. Intrafamily violence. Child. Adolescent.

Submetido em 24/03/2014

Aceito em 06/06/2014

\section{PARA INÍCIO DE CONVERSA...}

A violência faz parte de nossas vidas. Sob múltiplas formas e expressões, sua presença em nosso cotidiano faz com que sempre tenhamos alguma experiência ou opinião a transmitir quando, de algum modo, nos remetemos a ela. Trata-se de um fenômeno que exerce sobre nós fascínio e medo. Diante da violência, expressamos e demonstramos diferentes sentimentos. Enfim, a violência é um desses assuntos inquietantes. Assim, partindo dessas inquietações, propomo-nos a investigar a complexa, dinâmica e contraditória realidade da violência intrafamiliar psicológica contra crianças e adolescentes, com vistas a refletir, entender e, consequentemente, contribuir com o conjunto de discussões desenvolvidas no âmbito desse campo temático.

Temos, nos marcos deste artigo, a pretensão de discorrer sobre um tipo específico de violência, cuja ocorrência é frequente entre nós, mas que, contraditoriamente, em grande parte das vezes, é desconhecida, pois acontece de maneira silenciosa e velada, violentando e negando direitos de crianças e adolescentes no Brasil e no mundo. 
Para tanto, estamos ancorados nos resultados obtidos por meio da conclusão da pesquisa intitulada "Sobre o (in)dizível: violência intrafamiliar contra crianças e adolescentes em MossoróRN5", por meio da qual produzimos dados junto ao Centro de Referência Especializado da Assistência Social (CREAS), num lapso temporal que compreende os anos de 2009 a 2012, atentando, entre outras coisas, para as possíveis causas, a faixa etária e os principais agressores(as) desses sujeitos no município de Mossoró-RN.

Assim, inicialmente partiremos das reflexões de autores como Guerra (2008), Michaud (1989) e Faleiros e Faleiros (2008), destacando um conjunto de características que nos permitem compreender a violência, particularizando sua feição intrafamiliar. Em seguida, voltamo-nos especificamente para a análise de dados da violência psicológica intrafamiliar, em Mossoró-RN, tendo como balizadores os dados arrolados nos documentos investigados durante a realização da pesquisa de campo no CREAS. Por fim, apesar de ainda pairar uma série de incertezas e dúvidas sobre o fenômeno, compreendemos a necessidade de articular os pressupostos teóricos ou intelectuais a uma dimensão política voltada para o combate e a prevenção da violência contra crianças e adolescentes.

\section{ABRINDO O JOGO: REFLEXÕES SOBRE A VIOLÊNCIA}

O esforço teórico de pensar a violência psicológica contra crianças e adolescentes na particularidade de Mossoró-RN não pode acontecer descolado de outro esforço, qual seja: refletir, de modo breve e introdutório, sobre o fenômeno da violência de forma mais geral. De imediato, afirmamos ser este um fenômeno contraditório que, ao mesmo tempo, nos chama a atenção e nos afasta; é consentido e proibido na sociedade, repudiado e desejado; gritante e silencioso; (in)visível, (in)dizível e, até mesmo por essas características, de difícil compreensão.

5 Pesquisa do Programa Institucional de Bolsa de Iniciação Científica (PIBIC), vinculada ao Departamento de Serviço Social, da Faculdade de Serviço Social (FASSO) da Universidade do Estado do Rio Grande do Norte (UERN). 


\section{temporalis}

Cremos não ser possível determinar, com precisão, o momento histórico do surgimento da violência, até porque as diferentes formas de organizações econômicas, sociais, culturais e políticas que envolveram e envolvem as diversas sociedades materializaram-se como fatores determinantes para engendrar e subsidiar as percepções e concepções de violência presentes em seu interior. Ou seja, o fenômeno da violência não pode ser pensado a partir de um único prisma, mas deve ser analisado à luz das transformações históricas. A violência corre com o tempo e modifica-se, num movimento constante e ininterrupto. Portanto, ela se presta a múltiplas interpretações e significados os quais não estão descolados da época, cultura e sociedade em que são construídos. Dessa forma, as reflexões que estamos nos propondo a fazer nesse espaço têm a marca do nosso lugar no mundo, portanto, da nossa trajetória acadêmica, profissional e pessoal.

Têm sido constantes as tentativas e esforços empreendidos por diversos pesquisadores para conceituar a violência. Diante disso, não pretendemos, no limite deste artigo, esgotar as discussões ou engessar conceitos; iremos, tão somente, travar um pequeno diálogo com alguns deles, buscando relacionar as discussões empreendidas com a realidade concreta, seja aquela revelada por meio da pesquisa, seja aquela amparada em nossas análises e observações cotidianas.

Nesse sentido, exporemos dois conceitos usualmente utilizados para caracterizar a violência, no intuito de abstrairmos características gerais capazes de servir para nos nortear no entendimento dessa categoria. Para iniciarmos, trazemos o conceito da Organização Mundial de Saúde (OMS), segundo a qual a violência refere-se ao

[...] uso intencional da força física ou do poder, real ou potencial, contra si próprio, contra outras pessoas, contra um grupo ou comunidade, que resulte ou tenha grande possibilidade em resultar em lesão, morte, dano psicológico, deficiência de desenvolvimento ou privação (OMS, 2002).

Outro conceito interessante é o de Michaud (1989, p. 10-11), para quem 
há violência quando, numa situação de interação, um ou vários atores agem de maneira direta ou indireta, maciça ou esparsa, causando danos a uma ou várias pessoas em graus variáveis, seja em sua integridade física, seja em sua integridade moral, em suas posses, ou em suas participações simbólicas e culturais.

Os conceitos supramencionados, embora apontem para direções diferentes, nos trazem elementos que, a nosso ver, são fundamentais para discutirmos a violência, quais sejam: a existência de uma inter-relação entre sujeitos, de um lado, e as múltiplas consequências acarretadas por ela, de outro.

De fato, a violência é uma relação social e isso nos leva a uma dupla constatação: em primeiro lugar, ela não ocorre fora da sociedade, da rede de sociabilidades construída em seu interior; em segundo, ela é um fenômeno humano, portanto, só presente nas interações que os seres humanos produzem uns com os outros, com os animais ou com o mundo ao seu redor.

Como relação, ela é fundamentalmente desigual, pois, para que ocorra, um indivíduo ou grupo precisa se sobrepor em força, poder e/ou autoridade sobre outro indivíduo ou grupo. Esse indivíduo é um ser social que se faz único em meio aos outros animais por deter a capacidade teleológica, ou seja, a aptidão de pensar, raciocinar e refletir sobre os seus atos (MARX, 1996). Dessa forma, suas ações possuem uma intencionalidade que quando se materializa na violência traz consequências expressas, por exemplo, em dor, sofrimento ou até mesmo morte de outros seres humanos.

Por ser um ato teleológico, a violência não obedece a uma maneira predeterminada de existir. Em sua dimensão interpessoal, que aqui nos interessa mais especificamente, ela varia de sujeito para sujeito, sendo desencadeada, dentre outros aspectos, pelas ideias formuladas pelo sujeito, no caso o agressor, em sua mente; pelas condições objetivas com as quais ele se depara para materializá-la, bem como pelo grau de desenvolvimento material da sociedade, fazendo com que a violência passe a ser mais requintada do ponto de vista das armas e da maneira de utilizá-las ${ }^{6}$.

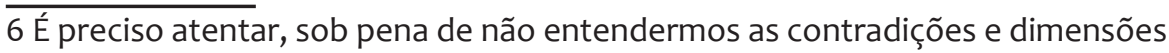




\section{tempordils}

Como relação social, a violência não se encontra circunscrita a um lugar ou tempo determinado, mas se espraia em todas as épocas, cantos e recantos da sociedade. Nesse sentido, poderíamos caracterizá-la como onipresente, pois, realmente, ela parece estar em todos os lugares ao mesmo tempo. Como já fizemos saber, a violência está presente na totalidade da vida social pelas relações que por ela ou nela se estabelecem e está intimamente relacionada à forma de compreendermos o mundo, individual ou socialmente. Ela está na rua, no trabalho, ou até mesmo nos locais considerados mais sagrados, como a Igreja e o lar. Parece não haver muros ou muralhas que possam freá-la.

É preciso também reforçar que, em meio a esse conjunto de fatores, a sociedade vem construindo diferentes justificativas para a violência, existindo aquela considerada legítima, cuja serventia se expressa na manutenção da "paz social" (como é o caso da violência policial, por exemplo), e aquela considerada ilegítima, pois colabora para quebrá-la (como a praticada por crianças e adolescentes infratores). Como afirmamos em outro momento deste texto, a violência corre e metamorfoseia-se com a história e, atualmente, algumas dessas suas facetas são rejeitadas pela sociedade, enquanto outras são comumente aceitas. Um fato parece inconteste: ninguém está imune a ela.

\section{QUEBRANDO O SILÊNCIO: VIOLÊNCIA INTRAFAMILIAR PSICOLÓGICA CONTRA CRIANÇAS E ADOLESCENTES EM MOSSORÓ-RN}

A partir de agora, discutiremos mais especificamente a violência psicológica intrafamiliar sem perder de vista que, como fenômeno mais amplo, a violência poderia ser caracterizada como uma relação social sustentada pelo poder, baseada no uso da força física, psicológica, individual e/ou coletiva, gerando

presentes nesse fenômeno, que o resultado do trabalho, expresso num objeto qualquer, desde um arco e flecha até uma bomba atômica, depois que se materializa na realidade concreta, ou melhor, quando passa a fazer parte da causalidade, nos termos de Lukács, ganha certa autonomia e independência de seu criador, fugindo de seu controle. Isso conforma o que Engels (2004) denominou "período de consequências". Assim, ainda que não seja nossa intenção eximir o ser humano de suas ações, precisamos contextualizá-las e compreender as múltiplas determinações que lhe conformam. 
rebatimentos físicos, psíquicos e/ou sociais para os sujeitos atingidos, em alguma medida, por ela. Por sua vez, a expressão intrafamiliar demonstra algo que se sucede no conjunto das relações familiares, ou seja, concretizado dentro das interações existentes entre os diferentes membros de uma família.

Portanto, a violência intrafamiliar contra crianças e adolescentes refere-se a todo ato ou omissão, pautado em relações de poder, que utiliza a força em suas diferentes variantes e concorre para transformar crianças e/ou adolescentes em objetos manipuláveis pelos adultos, gerando para eles consequências de ordem física, psicológica ou social, nem sempre visíveis (GUERRA, 2008). É importante destacar que esse fenômeno não está condicionado a um espaço físico determinado, posto que são os laços e relações mantidos entre os sujeitos que se mostram como determinantes para qualificarmos tal fenômeno dessa forma.

Destarte, a violência psicológica intrafamiliar contra crianças e adolescentes se dá por meio de ações ou omissões por parte dos pais e/ou responsáveis que concorram para prejudicar, de algum modo, o processo de desenvolvimento psicológico do sujeito. Tais ações conseguem se manifestar de diversas formas, a exemplo de insultos, humilhação, rebaixamento moral, ridicularização, não demonstração de afeto, dentre outros aspectos. Nas palavras de Guerra (2008, p. 33), "a violência psicológica também designada como tortura psicológica ocorre quando um adulto constantemente deprecia a criança, bloqueia seus esforços de autoaceitação, causando-lhe grande sofrimento mental". Segundo a autora, a violência psicológica quase sempre acompanha as demais violências intrafamiliares ${ }^{7}$ e é de difícil detecção, tendo em vista que suas marcas quase sempre não se mostram "a olho nu". De acordo com Faleiros e Faleiros (2008, p. 37):

A violência psicológica situa-se no conceito geral de violência como uso ilegítimo da autoridade decorrente de uma relação de poder. Assim, no lugar de oferecer a proteção, que é o seu dever, o adulto se relaciona com a criança por meio da agressão verbal ou psicológica e do domínio, substituindo e

7 Segundo Guerra (2008), há quatro modalidades de violência intrafamiliar contra crianças e adolescentes, quais sejam: física, psicológica, sexual e negligência. 


\section{temporalis}

invertendo o papel que dele se espera. Essa inversão da proteção em opressão configura uma "despaternalização", ou seja, a negação das funções sociais e pessoais dos papéis de pai e mãe, do poder familiar, muitas vezes ancorada em uma tradição autoritária da disciplina.

Com suas particularidades e pela forma como se concretiza, a violência psicológica, assim como as demais expressões da violência intrafamiliar, é uma realidade na vida de milhares de crianças e adolescentes em nossa sociedade, constituindo-se, como bem afirmam Faleiros e Faleiros (2008), por meio de uma inversão do papel dos membros da família que, em vez de proteger e construir uma relação baseada no afeto e respeito, oprimem e dominam suas crianças e adolescentes.

Seguramente, essa forma de tratamento para com os sujeitos supramencionados não é um fenômeno característico dos tempos hodiernos, muito embora não neguemos que as atuais configurações societárias tenham confluído para complexificá-lo a um novo patamar ${ }^{8}$. Ao nos reportarmos aos lastros temporais já transcorridos, verificamos que a história desses sujeitos teve a marca e a presença constante de diversas formas de violência. Em Mossoró-RN, lócus da pesquisa que deu suporte a este artigo, a realidade não é diferente. Nesse sentido, a partir desta seção, direcionaremos nossos esforços para desvelar a realidade investigada durante o transcurso da pesquisa?.

8 Como sabemos, nos primórdios da humanidade ou, como prefere Engels (2010, p. 37), na "infância do gênero humano", as condições de vida estavam assentadas numa situação geral de carência, determinada pelo parco desenvolvimento das forças produtivas. Nesse contexto de escassez, a violência aparecia fundamentalmente como forma de garantir os raros recursos necessários à manutenção da vida. Nas sociedades mais complexas, particularmente na capitalista, observamos que o desenvolvimento das forças produtivas criam as condições necessárias para romper com a situação de pauperia vivenciada outrora - embora isso não aconteça, integralmente, pelas próprias bases em que se assenta o sistema. Nessa nova conjuntura, a violência se complexifica e ganha novos contornos relacionados, em grande medida, mas não unicamente, a formas de dominação praticadas para manter a propriedade privada dos meios de produção.

9 A pesquisa de campo "Sobre o (in)dizível: violência intrafamiliar contra crianças e adolescentes em Mossoró-RN" foi realizada no Centro de Referência Especializada da Assistência Social (CREAS), onde consultamos os prontuários das crianças e dos adolescentes vítimas de violência intrafamiliar de janeiro de 
No Gráfico 1, apresentamos a situação da violência psicológica no município de Mossoró-RN, em relação às demais violências, mediante levantamento dos casos existentes no CREAS:

Gráfico 1 - Violência intrafamiliar contra crianças e adolescentes em Mossoró-RN (2009-2012)

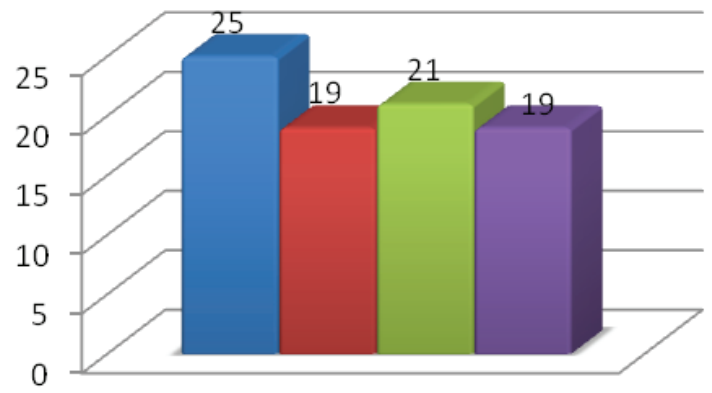

Violência Física

Violência Sexual

$\square$ Negligência

घ Violência Psicológica

Fonte: Sistematização dos autores, a partir de dados dos prontuários do CREAS/Mossoró-RN.

A análise dos dados mostra-nos uma diferença de aproximadamente seis casos, quando comparamos a ocorrência da violência física às demais. Num primeiro momento, ou melhor, na dimensão da aparência, isso poderia significar que ela acontece em maior proporção se confrontada com as outras formas. Todavia, da aparência à essência, somos levados a considerar a presença de inúmeras determinações, sobretudo de ordem social e cultural, responsáveis, em alguma medida, pelo alcance e (in) visibilidade adquiridos por elas e, sobremaneira, a psicológica, no âmbito institucional. Ademais, é preciso demarcar que estamos tratando com a violência denunciada, portanto, com o que autores como Faleiros e Faleiros (2008) denominam de "a ponta do iceberg", tendo em vista que os números relativos à denúncia são muito baixos em comparação à violência cotidiana sofrida por esses sujeitos.

Como demarcamos anteriormente, no transcurso da história, a infância e a adolescência têm sido alvo de inúmeras expressões da violência. Dentre elas, podem-se destacar a negligência

2009 a julho de 2012. 


\section{temporalis}

e as violências física, psicológica e sexual. Ao longo do tempo, elas vêm causando danos irreparáveis as crianças e adolescentes vitimados. É mister ressaltar que essas expressões da violência, embora se apresentem de forma separada, podem ocorrer conjuntamente, aumentando com isso seu potencial destrutivo.

Ora, quando atentamos para a ocorrência da violência psicológica em nível nacional, verificamos que ela alcançou, de acordo com o Mapa da Violência (2012), o terceiro lugar de atendimento no âmbito do Sistema Único de Saúde (SUS). Com isso, salta aos olhos sua invisibilidade no âmbito da Assistência Social, particularmente no município de Mossoró-RN, apontando a necessidade de um olhar mais arguto e analítico por parte da sociedade e dos profissionais que atuam na área.

Além disso, essa necessidade é fortalecida, à medida que é possível observar em todos os anos estudados, mesmo tomando o crescimento ocorrido em 2010, um pequeno número de casos registrados de violência psicológica, o que reforça os aspectos supramencionados. Vejamos como essa violência se expressa nos anos estudados:

\section{Gráfico 2 - Violência psicológica intrafamiliar contra crianças \\ e adolescentes em Mossoró-RN (2009-2012)}

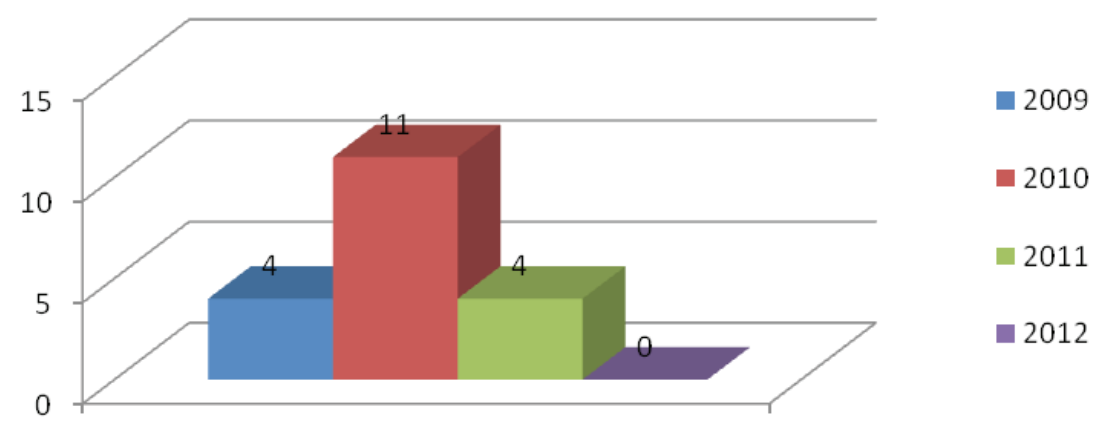

Fonte: Sistematização dos autores, a partir de dados dos prontuários do CREAS/Mossoró-RN.

No município de Mossoró, mais especificamente no ano de 2009, foram detectados quatro casos de violência psicológica, o que representou, à época, 15,38\% do total geral de ocorrências 
registradas pelo $\mathrm{CREAS}^{10}$. O percentual, embora não seja muito alto, não deve ser motivo de comemoração. A violência psicológica ${ }^{11}$, até mesmo por não deixar marcas visíveis, é bastante tolerada em nossa sociedade - o que não aponta, de modo algum, para a sua inexistência, mas para sua invisibilidade e para uma forte naturalização desse tipo de violência, dificultando, e por vezes até impedindo, a realização e, em alguns casos, o recebimento das denúncias. Noutras palavras:

Essa forma de violência é muito frequente e também a menos identificada como uma violência, em função do alto grau de tolerância da nossa sociedade frente a esse tipo de abuso. Praticamente ninguém denuncia ou responsabiliza pais, parentes, professores, policiais, profissionais da saúde e da assistência, entre outros, que desqualificam ou humilham crianças e adolescentes (FALEIROS; FALEIROS, 2008, p. 36).

A violência psicológica, em geral, parece só merecer atenção da sociedade quando vem acompanhada de outros tipos de violência considerados "mais graves" e, portanto, "mais sérios e preocupantes", resultando em um baixo número de denúncias desse tipo de violação de direitos, bem como em uma percepção que atenua sua existência e poder destrutivo sobre as crianças e adolescentes. Contudo, no que tange à violência, não nos parece interessante separar suas diferentes expressões como graves e não graves, perigosas e não perigosas, ou quaisquer outras

10 No âmbito deste artigo, não pretendemos fazer uma discussão pormenorizada sobre o CREAS, tendo em vista que nos propomos a pensar a violência intrafamiliar contra crianças e adolescentes. Entretanto, importa ressaltar que o CREAS, como integrante do Sistema Único de Assistência Social (SUAS), é articulador da proteção social especial de média complexidade, "sendo responsável pela oferta de orientação e apoio especializados e continuados de assistência social a indivíduos e famílias com seus direitos violados, mas sem rompimento de vínculos" (BRASIL, s/d, p. 4), tendo sido, por esse motivo, escolhido como espaço de coleta de dados para a nossa pesquisa.

11 Dois outros fatos merecem atenção: 1) no ano de 2009, dos quatro casos detectados, três não tinham registro do agressor, não sendo possível afirmar, com exatidão, se eram ou não casos de violência intrafamiliar, embora haja referência a isso nos prontuários; 2) a ausência de informações nos cadastros foi algo recorrente durante a produção dos dados, o que expressa, a nosso ver, um cenário marcado pela dificuldade de atendimento e prestação dos serviços à sociedade. 


\section{temporalis}

formas de hierarquia. Não estamos, com isso, querendo negar a existência de níveis de intensidade em que elas podem se expressar e, como corolário disso, danos de diversos graus, como pontuou Michaud (1989) mais acima. Todavia, é preciso atentar para algo importante: não raras vezes, a violência está inserida num ciclo que tem início com as formas consideradas mais brandas e "evolui" para estágios cada vez mais intensos, podendo inclusive, levar suas vítimas à morte. Daí a importância de não fazer separações e de combatê-la, independentemente da forma, nível ou espaços onde ocorra.

Dando prossecução a nossa análise, identificamos no ano de 2010 um aumento significativo, em relação ao período anterior, no número de casos detectados, passando para 11 e representando $22,44 \%$ do total de ocorrências registradas. Isso talvez se justifique devido à inserção de uma psicóloga no quadro de profissionais do CREAS, passando a atuar em conjunto com a assistente social e assim contribuindo para a identificação da violência psicológica. É relevante registrar que, nesse ano, a violência psicológica foi o segundo tipo que mais se evidenciou, estando abaixo apenas da violência física, que teve 18 ocorrências (36,73\%). Já em 2011, voltamos a observar somente quatro casos detectados nos prontuários do CREAS.

Em 2012 ${ }^{12}$, deparamo-nos com um dado surpreendente: a ausência de registros de casos de violência psicológica. Certamente, tal informação não aponta para a inexistência desse tipo de violência no município, mas para a não denúncia e para um processo de invisibilização que pode estar relacionado a diversos fatores, dentre os quais gostaríamos de particularizar dois, a nosso ver, bastante preocupantes: a possível existência de uma postura profissional de não registro dessas situações e a naturalização desse fenômeno por parte dos denunciantes ou dos responsáveis por receber a denúncia, que, nesse sentido, não compreenderiam as situações vivenciadas como violência.

Independentemente dos prováveis motivos que possam justificar posturas, tomadas de posição e encaminhamentos

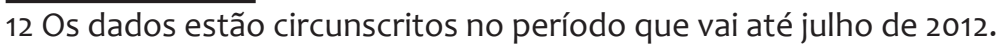


equivocados relativos às situações de violência cometidas contra crianças e adolescentes, não há como desconsiderar as responsabilidades que, enquanto família, instituições e/ou sociedade, de maneira geral, possuímos com esses sujeitos. Tampouco podemos discutir essa invisibilidade se não pensarmos que historicamente crianças e adolescentes foram submetidos a inúmeras formas de violência, sendo estas secundarizadas como problema na sociedade ou mesmo aceitas de maneira aberta ou velada.

Feitas essas ponderações, consideramos interessante pensar a faixa etária das crianças e/ou adolescentes vitimizados pela violência psicológica intrafamiliar, enquanto mais um importante indicador para compreendermos como esse fenômeno se expressa no município de Mossoró-RN, em contraposição aos direitos prescritos no âmbito do Estatuto da Criança e do Adolescente.

Gráfico 3 - Faixa etária das crianças e adolescentes vítimas de violência psicológica intrafamiliar em Mossoró-RN (2009-2012)

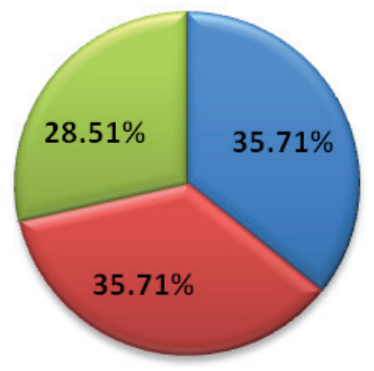

$\square$ e 8 anos

-9e 11 anos

$\square 12$ e 15 anos

Fonte: Sistematização dos autores, a partir de dados dos prontuários do CREAS/Mossoró-RN.

O principal alvo da violência psicológica intrafamiliar entre os anos de 2009 e 2012 foram crianças, com 71,42\% de incidência, seguidas dos adolescentes, com 28,51\%. Em geral, as crianças são mais vulneráveis às expressões da violência em todas as faixas etárias por possuírem menor capacidade de defesa e discernimento, se comparadas aos adolescentes. Grande parte dos adultos não as vê como sujeitos de direitos, mas como objetos manipuláveis de acordo com seus desejos e vontades, sendo legítimo, portanto, 


\section{temporalis}

praticar qualquer tipo de violência contra elas. Essas percepções ganham força na nossa cultura adultocêntrica, marcada pelo domínio do adulto em todas as esferas da sociedade.

Crianças e adolescentes aparecem historicamente como sujeitos invisíveis e desimportantes na sociedade ocidental, seja porque são vistos como descartáveis, já que facilmente são substituíveis (ARIÈS, 1981), seja porque não são considerados produtivos ou consumidores, portanto cidadãos de segunda categoria, como poderíamos supor que ocorre na sociedade capitalista.

O ECA bem como diversos outros ordenamentos internacionais ${ }^{13}$ buscam romper com essa visão que reduz crianças e adolescentes a objetos socialmente moldáveis e os pensa como sujeitos de direito, ou seja, cidadãos, portanto, pessoas inseridas em sociedade e participantes ativos dela. Nesse sentido, são pessoas com direitos e deveres, a quem se deve proteger e garantir vida, saúde, educação, convivência familiar e comunitária, dentre outros aspectos; pessoas a serem protegidas contra qualquer forma de violência, opressão ou agressão, independentemente de classe social, características físicas, credo ou quaisquer outros elementos que as caracterizem individual ou coletivamente.

O ECA se constitui, portanto, como um novo paradigma para enfrentar velhos problemas e, como tal, uma forma de pensar que vai de encontro a práticas arraigadas em nossa sociedade, como é o caso da violência contra esses sujeitos. Os dados acima (e também os apresentados abaixo) fazem-nos afirmar que o ECA e a luta da qual ele decorre foram os primeiros passos, mas há ainda uma longa jornada a ser percorrida para o reconhecimento e a concretização desses preceitos, pois, ainda hoje, passados quase 24 anos da sua existência, crianças são desrespeitadas,

13 A militância em prol dos direitos das crianças e adolescentes teve muitos protagonistas, dentre eles, em nível nacional, destacam-se: o Movimento Nacional de Meninas e Meninos de Rua (MNMMR), a Pastoral do Menor, o Fórum dos Direitos das Crianças e Adolescentes (Fórum-DCA) e outras Organizaçõos Não Governamentais (ONGs). As lutas empreendidas nesse campo eram balizadas pelas discussões dos organismos internacionais como a Convenção Nacional dos Direitos das Crianças e Adolescente (1989), as Regras de Beijing (1985) e as Diretrizes de Riad (1988) que vieram a se constituir como instrumentos importantes para a consolidação do Estatuto da Criança e do Adolescente (ECA). 
violentadas e reduzidas a objetos dos adultos, que deveriam lhes educar e proteger.

Gráfico 4 - Agressores da violência psicológica intrafamiliar contra crianças e adolescentes em Mossoró-RN (2009-2012)

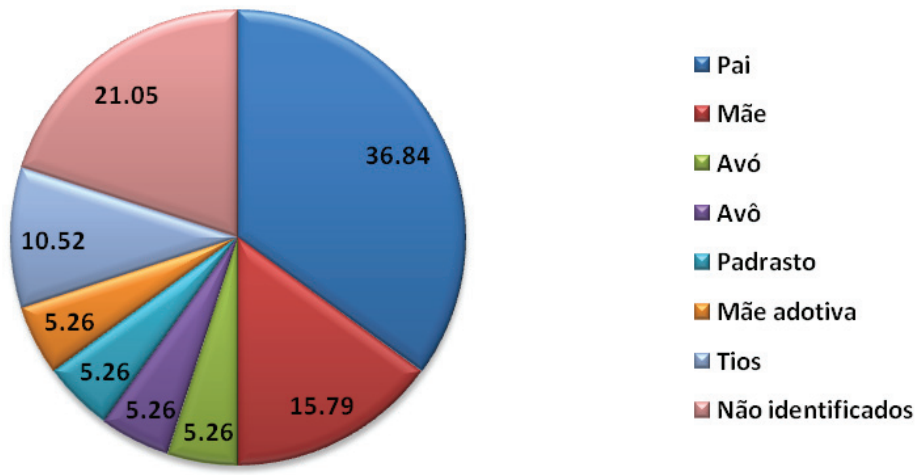

Fonte: Sistematização dos autores, a partir de dados dos prontuários do CREAS/Mossoró-RN.

Em consonância com a discussão feita anteriormente, as estatísticas revelam o pai como o que contribui com a maior prevalência para a violência psicológica (36,84\%), seguido de casos em que os agressores não foram identificados (21,05\%) e da mãe $(15,79)$, coincidindo com os dados de Azevedo e Guerra (2001) ${ }^{14}$, que também indicam o pai e a mãe como os principais responsáveis por esse tipo de violência. A violência intrafamiliar aponta, assim, para uma das contradições mais pungentes da nossa sociedade: aqueles que são responsáveis por proteger crianças e adolescentes mostram-se, na realidade, os principais violadores de seus direitos, deixando neles marcas visíveis e invisíveis que os acompanham no decorrer de suas trajetórias.

O fato de entre os principais agressores estarem, como nos mostram os dados, as figuras paterna e materna leva-nos a desmistificar a ideia segundo a qual a família e a gama de relações

14 Pesquisa Violência Psicológica Doméstica: vozes da juventude, realizada com 1.172 estudantes dos 5.547 calouros dos diversos cursos da Universidade de São Paulo (USP), em 2000. 


\section{temporalis}

estabelecidas nesse âmbito estão assentadas apenas em sentimentos positivos, como carinho e afeto. Dito de outra forma, conduz-nos a dessacralizar essa instituição. Conforme os dados, crianças e adolescentes são, de fato, violentados no seio dessa relação, fazendo ver as contradições e relações de poder existentes em seu interior. De acordo com Holanda (apud DIOGÉNES, 2008, p. 81):

Pensar o lugar que as famílias ocupam em contextos de violação de direitos de crianças e adolescentes é algo que representa um grande desafio. Há muitas interpretações que oscilam entre imagens ainda por demasiado sacralizadas dessa instituição social - a família - como se a ela fosse impossível associar situações profanas.

Diante da sacralização da família, costumamos, não raras vezes, formular um perfil de agressor que, geralmente, se afasta de seus membros ou das relações construídas em seu interior, como se os agressores fossem a ela inteiramente opostos ou estranhos. Essa análise tem particular importância neste estudo, pois, se de um lado, como já afirmamos nas linhas acima, a violência psicológica tende a ser invisibilizada, de outro, a imagem historicamente construída em torno da família é, a nosso ver, um fator responsável por exponenciar ainda mais o processo de miopia atrelado aos casos que envolvem o tipo de violência em questão.

Outro aspecto a ser discutido diz respeito à cultura adultocêntrica presente em nossa sociedade e que, sob nosso ponto de vista, faz eco com as expressões da violência intrafamiliar contra crianças e adolescentes. Vivemos em uma sociedade polarizada: de um lado, encontram-se os dominantes, de outro, os dominados. As relações entre os polos se pautam na dominação do mais forte sobre o mais fraco. Isso se dá tanto nas macro como nas microrrelações. Espaços como a família aparecem como simulacros de uma realidade mais ampla, portanto, perpassada por relações de dominação e poder, o que Saffioti (2007) denomina como macro e micro poderes, sendo que quando nos referimos à violência cometida contra crianças e adolescentes, particularmente no 
interior das relações familiares, entra em jogo mais fortemente esse último. Nas palavras da autora:

\begin{abstract}
Mas se a vitimização de crianças dependesse apenas do exercício do macropoder, o número de vítimas seria, certamente, menor. A vitimização de crianças constitui fenômeno extremamente disseminado, exatamente porque o agressor detém pequenas parcelas de poder, sem deixar de aspirar ao grande poder. Em não se contentando com sua pequena fatia de poder e sentindo necessidade de se treinar para o exercício do grande poder, que continua a almejar, exorbita de sua autoridade, ou seja, apresenta a síndrome do pequeno poder (SAFFIOTI, 2007, p. 17, grifos do autor).
\end{abstract}

Segundo a autora, a síndrome do pequeno poder se constitui nas relações em que se exerce o pequeno poder de forma arbitrária, em que o sujeito dominado em outras esferas da vida social, "[...] consciente de seu diminuto poder, de seu não poder, trata de ampliá-lo ou criá-lo na relação interpessoal que estabelece, efêmera ou duradouramente, com outra pessoa" (SAFFIOTI, 2007 , p. 19). Trata-se, portanto, no contexto aqui estudado, do adulto que em sua relação com a criança a humilha, maltrata, agride ou oprime.

Esse sujeito pratica tais atos de forma socialmente legítima, tomando por base sua força enquanto sujeito dominante. Ele age como alguém vivendo em uma sociedade ancorada em uma cultura adultocêntrica, por meio da qual o adulto é compreendido como o elemento central e mais importante nas relações sociais e, portanto, como aquele superior, ou detentor de poder. Tudo gira ao seu redor e, ao menos nas microrrelações, ele é o dominante, aquele cujas atitudes não podem ser questionadas.

Assim, embora comecemos a vislumbrar mudanças em nossa sociedade, o adulto ainda pode, desde que em graus e intensidades "aceitáveis", castigar, bater, gritar, enfim, agir em relação a crianças e adolescentes de maneira a torná-los adultos, à sua imagem e semelhança. Os adultos, embebidos da sua condição, submetem crianças a suas próprias regras, reduzindo-as à condição de objetos outrora vivenciada por eles. Vivemos em uma 


\section{temporalis}

sociedade que ainda legitima essas práticas e isso pode ser observado nos dados aqui trazidos, pois eles apontam para o silêncio do Estado, da sociedade, da família e, portanto, dos sujeitos individuais em relação à violência intrafamiliar psicológica ocorrida com crianças e adolescentes.

Não podemos deixar de considerar que nem todos se calam diante da violência, as denúncias aqui analisadas, mesmo com pequenos percentuais, demonstram isso. Atualmente, são crescentes as vozes daqueles que se erguem na luta pelos direitos das crianças e adolescentes, particularmente contra a violência perpetrada contra eles. Entretanto, concordamos com Saffioti (2007) quando afirma que uma mudança plena nessa situação somente será possível no momento em que construirmos relações sociais de igualdade em todos os níveis da sociedade, inclusive entre adultos e crianças; relações em que diferenças não sejam transformadas em desigualdades e em que o respeito seja o elemento fundamental.

Vejamos agora um outro dado que pode contribuir para nossa análise:

Gráfico 5 - Sexo das vítimas da violência psicológica intrafamiliar denunciada no CREAS/Mossoró-RN (2009-2012)

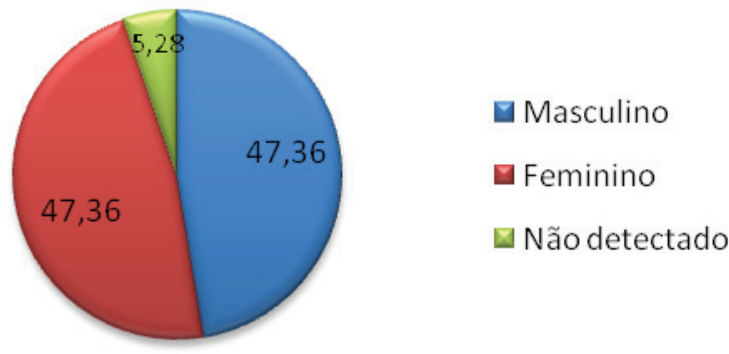

Fonte: Sistematização dos autores, a partir de dados dos prontuários do CREAS/Mossoró-RN.

A análise dos dados acima expostos nos revela que não existiram, do ponto de vista da condição sexual, diferenças significativas entre os sujeitos vitimados com a ocorrência da violência psicológica. Não fossem os casos não identificados $(5,28 \%)$, 
estaríamos diante de uma equivalência. Não estamos, com isso, pretendendo fazer deduções com vistas a relacionar, de maneira imediata, o sexo da vítima ao tipo de violência que a acomete, pois, como já apontamos, a violência não escolhe raça, cor, credo, classe social ou sexo, estando presente em todos os espaços sociais e perpassando diferentes relações, mas seria ingênuo pensar que isso se dá de forma igualitária.

Portanto, podemos afirmar que alguns aspectos inscritos na totalidade da vida social favorecem ou desfavorecem a incidência de determinada violência sobre um sexo específico. Por exemplo, na esteira desta mesma pesquisa, investigamos a violência sexual e, quando da materialização dos dados, observamos uma acentuada divergência entre o percentual de vítimas do sexo feminino $(78,57 \%)$ em relação àquelas do sexo masculino $(21,43 \%)$, demonstrando que alguns grupos são mais vulneráveis que outros a determinadas expressões da violência.

A análise realizada sobre o fenômeno aponta, portanto, o pressuposto de que, entre outros aspectos, os recortes culturais e de gênero (responsáveis por demarcar o papel e o lugar do ser mulher na sociedade), presentes muito fortemente em nossa formação sócio-histórica, exercem um papel importante, para entendermos o porquê de as crianças e adolescentes do sexo feminino serem mais atingidas pela violência sexual ou mesmo por compreendermos por que meninos e meninas são quase igualmente atingidos pela violência psicológica.

Assim, não podemos deixar de considerar que a violência não é tão democrática quanto parece à primeira vista. Se as diferenças se transformam em desigualdades na sociedade capitalista e se pensamos que isso se configura por meio de uma relação de poder, não podemos deixar de considerar que a violência é perpassada por essas desigualdades ou assimetrias. Portanto, diferenças de gênero, classe social, etnia são fatores presentes no modo como a violência se expressa e não podem ser desconsideradas na análise.

No caso da nossa pesquisa, os dados presentes nos prontuários invisibilizam tais aspectos, pois não há senão em três deles 


\section{temporalis}

referências a classe social, nível de escolaridade ou raça dos agressores, tampouco dos agredidos, impossibilitando tal análise.

São muitos os silêncios que rodeiam e compõem a violência psicológica intrafamiliar. Embora ela se concretize em gritos, agressões verbais, ausência de carinho, cuidado e proteção e acompanhe quase sempre as demais expressões da violência, as paredes e muros que a rodeiam ainda são imensos. Os dados aqui trazidos demonstram e fazem eco com o silêncio que a cerca. Se há consonância da sociedade com as marcas visíveis da violência física e sexual, essa aceitação é ainda mais forte se pensarmos as marcas "invisíveis" da violência psicológica.

\section{CONCLUSÕES: CONTRIBUINDO PARA O FIM DO SILÊNCIO}

No decorrer deste texto, trouxemos uma compreensão da violência que a concebe como um fenômeno social, humano e histórico, multifacetado, multideterminado, e que, ao contrário do comumente propagado, não se exerce apenas no nível do corpo, incidindo também no processo de desenvolvimento psicológico e mental dos sujeitos, como ocorre através da violência psicológica intrafamiliar contra crianças e adolescentes, por exemplo.

Os dados apresentados neste artigo apontam para uma oscilação entre o número (a nosso ver reduzido e distante da realidade concreta) denunciado de casos de violência psicológica intrafamiliar em Mossoró, num lapso temporal que compreende os anos entre 2009 e 2012. A presença/existência desses casos pode ser explicada por diversos fatores, que vão desde as particularidades e singularidades que cercam esse tipo de violência até as dificuldades na prestação dos serviços dos órgãos e instituições que atuam com essa problemática.

Contudo, quaisquer que sejam os fatores, essa situação nos aponta a candente necessidade de quebrar o silêncio, de não aceitar uma realidade que cala, um silêncio que violenta tanto quanto as palavras. É necessário desvendar a violência intrafamiliar contra crianças e adolescentes, tendo em mente que não podemos compactuar com nenhuma das suas expressões, mesmo com aquelas que, por serem naturalizadas, são consideradas mais brandas, como a violência psicológica. 


Quebrar
quebrando
quebrantando
quebrar para tanto
quebrar para romper o pranto
transformar o pranto em música
transformar a música em vida
viva para quebrar a rotina
rotina que parece silêncio
silêncio pra ser quebrado
romper o silêncio
rachar com a vida
calar o pranto
ouvir a música
(Toni Godoy)

\section{REFERÊNCIAS}

ARIÈS, P. História Social da Criança e da Família. 2. ed. São Paulo: LTC (Grupo GEN), 1981.

AZEVEDO, M.A.; GUERRA, V. N. A. Violência Psicológica Doméstica: vozes da juventude. São Paulo: Laboratório de Estudos da Criança (LACRI), 2001.

BRASIL. Estatuto da Criança e do Adolescente. In: CRESS SER. Lei 8.069, de 13 de julho de 1990. Coletânea de Leis. Porto Alegre, 1996-1999.

- Ministério do Desenvolvimento Social e Combate a fome. Centro de Referência Especializado de Assistência Social - CREAS. Guia de Orientação n. 01. $1^{\text {a }}$ versão. Brasília-DF, s/d. (mimeo).

DIÓGENES, G. Os sete sentimentos capitais: exploração sexual comercial de crianças e adolescentes. 2. ed. São Paulo: Annablume, 2008. 


\section{temporalis}

ENGELS, F. A origem da família, da propriedade privada e do Estado. Tradução de Leandro Konder. 2. ed. São Paulo: Expressão Popular, 2010.

. Sobre o papel do trabalho na transformação do macaco em homem. In: ANTUNES, Ricardo (Org.). A dialética do trabalho: escritos de Marx e Engels. São Paulo: Expressão Popular, 2004.

FALEIROS, V. P.; FALEIROS, E. S. Escola que protege: enfrentando a violência contra crianças e adolescentes. 2. ed. Brasília, 2008.

GUERRA, V. N. A. Violência de pais contra filhos: a tragédia revisitada. 6. ed. São Paulo: Cortez, 2008.

KRUG, E. G. Relatório mundial sobre violência e saúde. Genebra: Organização Mundial da Saúde, 2002.

MARX, K. O capital: crítica da economia política. v. 1. Livro 1. São Paulo: Nova Cultural Ltda, 1996.

MICHAUD, Y. A violência. São Paulo: Ática, 1989.

RIBEIRO, M. M; MARTINS, R. B. Violência doméstica contra crianças e adolescentes: a realidade velada e desvelada no ambiente escolar. $6^{\text {a }}$ reimp. Curitiba: Juruá, 2009.

SAFFIOTI, H. I. B. A Síndrome do pequeno poder. In: AZEVEDO, Maria Amélia; GUERRA, Viviane Nogueira de Azevedo (Org.). Crianças Vitimizadas: a síndrome do pequeno poder. Ed. amp. 2. ed. São Paulo: Iglu, 2007. p. 49-95.

SILVA, H. O. Marco conceitual da violência contra a Criança e o Adolescente: análise da Violência contra a Criança e o Adolescente, segundo o Ciclo de Vida no Brasil. São Paulo: Global/Unicef, 2005.

WAISELFISZ, J. J. Mapa da violência 2012: crianças e adolescentes do Brasil. Disponível em: <mapadaviolencia.org.br/pdf2012/ MapaViolencia2012_Criancas_e_Adolescentes.pdf>. Acesso em: 18 mar. 2013. 